OAJIS

Open Access

Journal of

Information

Systems

is.its.ac.id/pubs/oajis/

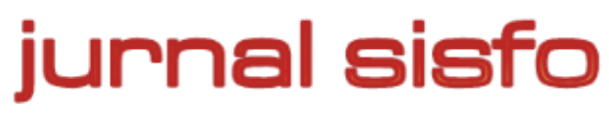

Jurnal Sisfo Vol. 06 No. 02 (2017) 199-214

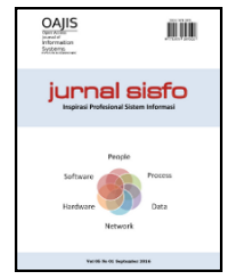

\title{
Pembuatan Prosedur Operasional Standar Pengelolaan Insiden pada Government Resources Management Systems Kota Surabaya Berdasarkan ITIL V3
}

\author{
Ammyra Fatma Rizky, Anisah Herdiyanti ${ }^{*}$, Tony Dwi Susanto \\ Jurusan Sistem Informasi, Fakultas Teknologi Informasi, Institut Teknologi Sepuluh Nopember (ITS)
}

\begin{abstract}
Surabaya has implemented e-government namely Government Resource Management Systems (GRMS) into every unit's operational activities. Apart from its implementation success, all incidents occured when using the GRMS are managed by a unit called Bina Program. It is mainly an ad-hoc process whereby Bina Program assign a group of people as an admin to handle the incidents. Furthermore, there is no logging activities to record the status of the incidents. Therefore, the development of standard operational procedure (SOP) is necessary in order to improve the quality of government services. This research calls for the problems by proposing SOP for incident management based on ITIL V3 international standard and Peraturan Menteri Number 12. The research developed 3 (three) SOP, i.e. SOP for incident amangement, SOP for major incident management, and SOP for managing incident logging. The SOP for incident management can help to avoid role conflict and maintain the quality of services.
\end{abstract}

Keywords: Standard Operational Procedure (SOP), Incident Management, Gap Analysis, ITIL V3

\begin{abstract}
Abstrak
Penerapan Government Resource Management Systems (GRMS) telah mendukung aktivitas pemerintahan seluruh Satuan Kerja Perangkat Daerah (SKPD) di Kota Surabaya. Terlepas dari kesuksesan aplikasi e-government tersebut yang telah menjadi acuan bagi kota-kota lain di Indonesia, insiden yang berkaitan dengan operasional GRMS masih dikelola secara ad-hoc oleh Bagian Bina Program. Insiden langsung ditangani oleh admin, dan pelaporannya belum tercatat secara rutin. Belum adanya kategorisasi dan prioritas kian mendorong penyelesaian insiden yang kurang optimal. Standarisasi proses pengelolaan insiden terkait GRMS menjadi penting dalam bentuk prosedur operasional standar (SOP). Pembuatan SOP didasarkan pada kesenjangan aktivitas terkini dengan aktivitas dalam Proses Pengelolaan insiden berdasarkan ITIL V3. Format penyusunan didasarkan pada Peraturan Menteri Nomor 12. Penelitian ini menghasilkan 3 (tiga) SOP, yaitu: SOP Penanganan Insiden, SOP Penanganan Major Incident dan SOP Rekapitulasi Log Insiden. Dengan adanya SOP, pengelolaan insiden dapat dibakukan, dimonitor dan diawasi sehingga operasional GRMS dapat dipastikan mendukung aktivitas pemerintahan SKPD secara kontinyu.
\end{abstract}

Kata kunci: Standard Operating Procedure, Incident Management, Analisis Kesenjangan, ITIL V3

(C) 2017 Jurnal SISFO.

Histori Artikel : Disubmit 25 Juli 2016; Diterima 18 Januari 2017; Tersedia online 24 Januari 2017

${ }^{*}$ Corresponding Author

Email address: anisah@is.its.ac.id (Anisah Herdiyanti) 


\section{Pendahuluan}

Aktivitas pemerintahan pada tiap Satuan Kerja Pemerintah Daerah (SKPD) Pemerintah Kota Surabaya telah didukung oleh Government Resource Management Systems (GRMS) yang dikelola oleh Bagian Bina Program [1]. Sistem ini terdiri atas enam sistem yang saling terintegrasi, yaitu E-Budgeting, E-Project, EProcurement, E-Delivery, E-Controlling, dan E-Performance. Kegiatan operasional yang didukung aplikasi tersebut tidak terlepas dari adanya gangguan atau kerusakan yang disebabkan oleh lingkungan dan manusia, diantaranya kerusakan aplikasi dan kehilangan data. Kerusakan yang terjadi tidak hanya berdampak pada kemampuan teknologi yang digunakan, tetapi juga berpotensi memberikan dampak pada kegiatan operasional pelayanan publik. Bila tidak ditangani secara khusus, selain akan menghadapi risiko operasional, juga akan mempengaruhi risiko reputasi dan berdampak pada menurunnya tingkat kepercayaan publik. Oleh sebab itu perlu dilakukan pengelolaan terhadap insiden sehingga dapat mengoptimalkan dukungan terhadap aktivitas pemerintahan SKPD. Pengelolaan insiden perlu dibakukan dalam langkah-langkah terpadu untuk menjamin keberlangsungan layanan agar tetap dapat berfungsi dengan baik terutama dalam penggunaan layanan TI [2].

Bagian Bina Program telah melakukan aktivitas pengelolaan terhadap insiden yang berkaitan dengan GRMS dengan menggunakan aplikasi e-trac, namun mengalami beberapa permasalahan, diantaranya: kehilangan informasi status insiden karena tidak dilakukannya pencatatan secara berkala; tumpang tindih penyelesaian insiden karena tidak adanya prioritasi untuk seluruh insiden yang masuk; dan penumpukan pekerjaan karena status insiden yang tidak diperbarui oleh pengembang (developer). Di sisi lain, pengguna aplikasi kian bertambah dan kompleksitas sistem kian berkembang akibat penerapan GRMS untuk mendukung penuh aktivitas internal pemerintahan di seluruh SKPD. Tanpa adanya proses yang baku dalam mengelola insiden maka akan berakibat pada ketidakmampuan memberikan layanan terkait GRMS secara optimal. Keberadaan Prosedur Operasional Standar, atau yang lebih dikenal dengan Standard Operational Procedure (SOP) menjadi penting untuk mengontrol perilaku organisasi secara baku dan terstandar [3].

Penelitian ini berfokus kepada pembuatan Prosedur Operasional Standar (SOP) untuk pengelolaan insiden terkait GRMS yang dikelola oleh Bagian Bina Program. Acuan yang digunakan dalam pembuatan SOP adalah standar internasional ITIL V3 mengenai proses pengelolaan insiden (incident management) dan format penyusunan SOP pemerintah yang diatur melalui Peraturan Menteri Pendayagunaan Aparatur Negara dan Reformasi Birokrasi Republik Indonesia Nomor 35 Tahun 2012 Tentang Pedoman Penyusunan Standar Operasional Prosedur Administrasi Pemerintahan. Pendekatan yang digunakan untuk pembuatan aktivitas dalam SOP mengacu pada kesenjangan aktivitas kekinian (existing) pengelolaan insiden oleh Bagian Bina Program dengan aktivitas terstandar (ideal) pengelolaan insiden berdasarkan proses incident management ITIL V3. Dengan adanya SOP pengelolaan insiden tersebut diharapkan dapat meningkatkan kinerja penanganan insiden secara terstruktur sesuai dengan standar sehingga dapat meningkatkan kualitas layanan terkait GRMS.

\section{Tinjauan Pustaka/Penelitian Sebelumnya}

\subsection{Government Resource Management Systems (GRMS)}

Bagian Bina Program telah mendukung program penerapan e-government di seluruh Satuan Kerja Perangkat Daerah (SKPD) di Kota Surabaya melalui penerapan Government Resource Management Systems atau yang disingkat dengan GRMS. Aplikasi tersebut mendukung kelompok aktivitas pengelolaan keuangan daerah dengan dukungan 6 (enam) aplikasi dasar, yaitu: E-Budgeting, E-Project, EProcurement, E-Delivery, E-Controlling, dan E-Performance [1]. Penjelasan masing-masing aplikasi tersebut akan dipaparkan secara singkat sebagai berikut: 
1) Aplikasi E-Budgeting memfasilitasi proses penyusunan Anggaran Pendapatan dan Belanja Daerah (APBD), pengusulan revisi - termasuk Perubahan Anggaran Kegiatan (PAK) sehingga anggaran dapat sesuai dengan Rencana Pembangunan Jangka Menengah Daerah (RPJMD), nilai dan rekening lebih akurat serta akuntabel.

2) Aplikasi E-Project memudahkan dalam perencanaan paket-paket pekerjaan yang telah disetujui alokasi anggarannya sehingga pelaksanaan anggaran dapat dikelola secara terintegrasi.

3) Aplikasi E-Procurement menyediakan fasilitas pelayanan pengadaan barang atau jasa secara elektronik yang mendukung peningkatan transparansi dan akuntabilitas, memperbaiki tingkat efisiensi proses pengadaan, serta mendukung proses monitoring dan evaluasi proses pengadaan.

4) Aplikasi E-Delivery merupakan sistem pendukung administrasi kegiatan, mulai dari pembuatan kontrak pengadaan barang atau jasa beserta dokumen kelengkapannya.

5) Aplikasi E-Controlling menyediakan fasilitas monitoring penyelenggaraan paket pekerjaan yang disetujui dengan membandingkan rencana yang dibuat dalam aplikasi E-Project

6) Aplikasi E-Performance merupakan sistem informasi manajemen kinerja pegawai sesuai dengan Peraturan Walikota No. 21 Tahun 2015 tentang Petunjuk Teknis Pemberian Uang Kinerja pada Belanja Langsung kepada PNSD di Lingkungan Pemerintah Kota Surabaya agar terwujud penilaian prestasi yang lebih objektif, terukur, akuntabel, partisipasif dan transparan.

Dalam penelitian ini, GRMS diangkat sebagai objek studi pengelolaan insiden yang akan distandarisasi prosesnya melalui penyusunan prosedur operasional standar (SOP). Pengelolaan insiden yang dilakukan oleh Bagian Bina Program dialokasikan kepada masing-masing admin yang menjadi penanggung jawab Satuan Kerja Perangkat Daerah (SKPD). Penjelasan lebih lanjut mengenai SOP akan dipaparkan dalam subbagian berikut sementara penjelasan mengenai kondisi terkini pengelolaan insiden oleh Bagian Bina Program akan dipaparkan pada Bagian Hasil dan Pembahasan.

\subsection{Prosedur Operasional Standar (SOP)}

Secara definitif, Prosedur Operasional Standar - atau yang dikenal dengan Standard Operational Procedure (SOP) merupakan acuan untuk melaksanakan tugas pekerjaan sesuai denga fungsi dan alat penilaian kinerja instansi pemerintah berdasarkan indikator-indikator teknis, administratif dan prosedural sesuai tata kerja, prosedur kerja dan sistem kerja pada unit kerja yang bersangkutan [3]. Griffin [4] menyebutkan bahwa SOP menguraikan langkah-langkah langkah-langkah yang harus dilaksanakan pada keadaan tertentu sementara Wicaksana et al [5] berpendapat bahwa Prosedur Operasional Standar (SOP) dapat memastikan perilaku pengguna terhadap sistem sesuai denganstandar yang diacu.

Secara konten, Prosedur Operasional Standar (SOP) terdiri dari 2 (dua) macam unsur, yaitu: Unsur Dokumentasi dan Unsur Prosedur [6]. Unsur Dokumentasi menjelaskan informasi yang dibahas dalam sebuah SOP, mencakup: a) Halaman Judul, b) Keputusan Pimpinan, c) Daftar Isi, dan d) Penjelasan Singkat Penggunaan; sementara Unsur Prosedur menjelaskan informasi yang meliputi: a) Bagian Identitas dan b) Bagian Flowchart beserta penjelasannya. Dengan adanya SOP dapat diperoleh manfaat, diantaranya: menstandarkan aktivitas dan ukuran standar kinerja sehingga dapat memingkatkan efisiensi dan efektivitas pelaksanaan tugas dan tanggung jawab pelaksana kegiatan.

Penelitian ini mengacu kepada penyusunan prosedur berdasarkan Peraturan Menteri Pendayagunaan Aparatur Negara dan Reformasi Birokrasi Republik Indonesia Nomor 35 Tahun 2012 Tentang Pedoman Penyusunan Standar Operasional Prosedur Administrasi Pemerintahan. Jenis studi kasus yang merupakan organisasi pemerintah menjadi pertimbangan utama dalam penggunaan aturan tersebut sebagai acuan dalam penyusunan prosedur. 


\subsection{Incident Management}

Incident management adalah merupakan istilah dalam proses pengelolaan layanan teknologi informasi (TI) mengacu kepada kerangka kerja ITIL V3. Berdasarkan definisinya, proses pengelolaan insiden (incident management) menggambarkan sebuah interupsi atau pengurangan kualitas dari layanan TI. Tujuan dari pengelolaan insiden adalah untuk mengembalikan layanan kembali normal dengan secepat mungkin dan untuk meminimalkan dampak merugikan pada operasi bisnis. Proses ini melibatkan serangkaian aktivitas, yaitu: a) identifikasi insiden (incident identification); b) pencatatan Insiden (incident logging); c) pengkategorisasian insiden (incident categorization); d) prioritas Insiden (incident prioritization); e) diagnosis awal (initial diagnosis); f) eskalasi insiden (incident escalation); g) diagnosis dan investigasi (investigation and diagnosis); h) resolusi dan pemulihan (resolution and recovery); serta i) penutupan insiden (incident closure) [7].

Pembahasan Prosedur Operasional Standar (SOP) dalam penelitian ini difokuskan kepada proses pengelolaan insiden yang mengacu kepada aktivitas berdasarkan kerangka kerja ITIL V3. Objek pengelolaan insiden adalah GRMS yang dikelola oleh Bagian Bina Program Pemerintah Kota Surabaya.

\subsection{Service Desk}

Pengertian dasar dari service desk adalah bagian dari iterasi service operation yang menjadi SPOC (Single Point of Contact) antara penyedia layanan dan pengguna layanan. Service desk berfungsi untuk mengelola incident management, request fulfillment dan menangani komunikasi dengan pengguna layanan. Tujuan utama dari service desk adalah sebagai jembatan komunikasi antara penyedia layanan dan pelanggan. Implementasi service desk beragam pada masing-masing organisasi. Service desk dibentuk menyesuaikan kebutuhan TI dalam mengelola insiden dan problem pada layanan [8].

Fungsi service desk di Bagian Bina Program Pemerintah Kota Surabaya dikelola langsung oleh admin yang menjadi penanggung jawab masing-masing Satuan Kerja Perangkat Daerah (SKPD). Admin bertindak sebagai penanggung jawab, komunikasi dengan pengguna maupun menangani insiden dan permintaan yang masuk. Penelitian ini akan mengusulkan penambahan aktor dan role untuk Bagian Bina Program terkait dengan fungsi Service Desk. Acuan penambahan tersebut adalah proses pengelolaan insiden berdasarkan ITIL V3.

\subsection{Analisis Kesenjangan}

Menurut [9], analisis kesenjangan merupakan akitivitas membandingkan kondisi aktual dengan kondisi ideal. Hal ini dapat menjadikan evaluasi bisnis yang memfokuskan pada kesenjangan kondisi aktual dengan kondisi ideal. Analisis kesenjangan dapat mengindetifikasi proses-proses yang perlu dilakukan untuk mengurangi kesenjangan agar tercapainya kondisi yang ideal [9].

\section{Metodologi}

Gambar 1 akan dipaparkan lebih lanjut sebagai berikut.

\subsection{Tahap Penggalian Data}

Tahap ini merupakan tahap pertama dalam penelitian ini. Penggalian kondisi kekinian insiden bertujuan untuk memahami keadaan kekinian pada GRMS. Terdapat dua aktivitas dalam penggalian data, yaitu: persiapan melalui penyusunan interview protocol dan pelaksanaan melalui penggalian data berdasarkan interview protocol yang dibuat. Masukan dari penyusunan interview protocol adalah hasil dari studi literatur mengenai analisis kesenjangan, pengelolaan insiden ITIL V3 serta pedoman penyusunan SOP serta dokumen Peraturan Walikota Kota Surabaya dan pedoman penyusunan SOP berdasarkan Permenpan 
No. 35 tahun 2012; sementara penggalian data direncanakan melalui wawancara kepada admin dan pengembang (developer) Bagian Bina Program selaku karyawan yang mengelola insiden terkait Government Resource Management Systems (GRMS). Luaran dari tahap ini adalah hasil penggalian data.

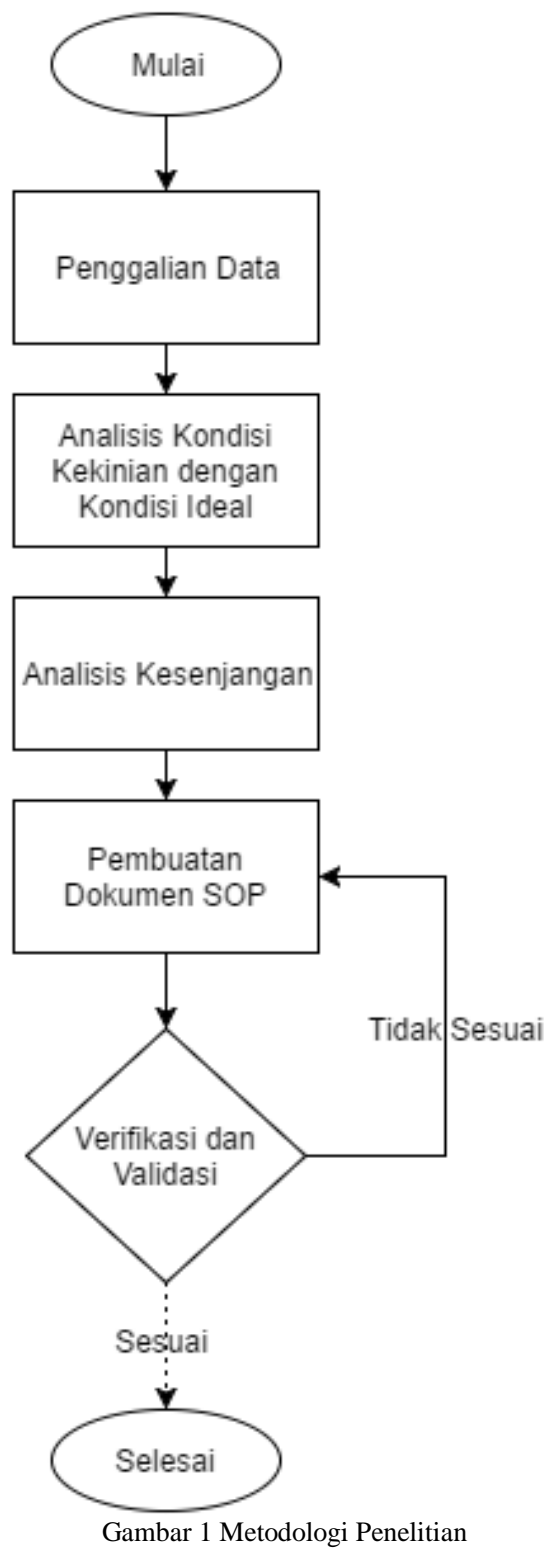

\subsection{Tahap Analisis Kondisi Kekinian dengan Kondisi Ideal}

Dalam tahap ini, analisis dilakukan terhadap hasil penggalian data dengan melakukan analisis kondisi kekinian dan mengkaitkan hasil analisis tersebut dengan kondisi ideal. Luaran dari tahapan ini adalah hasil analisis kondisi kekinian beserta keterkaitannya dengan kondisi ideal. 


\subsection{Tahap Analisis Kesenjangan}

Tahap analisis kesenjangan bertujuan untuk evaluasi kesenjangan yang terjadi antara kondisi kekinian yang sedang berjalan sekarang dengan kondisi ideal standar acuan ITIL V3. Masukan dari analisis kesenjangan berupa hasil analisis kondisi kekinian beserta keterkaitannya dengan kondisi ideal, lalu dilakukan analisis kesenjangan dengan mengidentifikasi aktivitas yang ada di kondisi ideal namun tidak ada di kondisi eksisting. Selanjutnya diidentifikasi perubahan dan dampak dari hasil kesenjangan tersebut. Luaran dari aktivitas ini berupa tabel analisis kesenjangan yang dapat berupa hasil kesenjangan yang terjadi, temuan perubahan pada prosedur yang telah ada, dan dampak dari perubahan kesenjangan.

\subsection{Tahap Pembuatan Dokumen SOP}

Tahap pembuatan dokumen SOP merupakan tahap keempat dari penelitian ini. Dalam tahap ini penulis akan membuat SOP sebagai luaran dari penelitian ini. Di dalam tahap ini terdapat satu aktivitas yang dilakukan, yaitu membuat dokumen SOP. Luaran dari aktifitas ini berupa dokumen SOP pengelolaan insiden yang belum terverifikasi dan tervalidasi.

\subsection{Tahap Verifikasi dan Validasi}

Verifikasi dan validasi bertujuan untuk memastikan bahwa dokumen SOP yang dibuat telah sesuai dengan kebutuhan masing-masing GRMS. Dalam melakukan verifikasi dokumen SOP, penulis akan menggunakan teknik wawancara dengan admin GRMS sebagai penanggung jawab proses dan kepala sub bagian untuk memverifikasi adanya penambahan aktor dan role baru untuk Bina Program. Setelah dilakukan verifikasi dokumen SOP pengelolaan insiden, penulis akan melakukan validasi dokumen SOP dengan melakukan uji coba secara langsung dengan pihak-pihak yang berwenang dalam GRMS dengan memberikan skenario kepada kepala sub bagian. Dari situ kepala sub bagian menunjuk staffnya untuk melakukan skenario yang penulis buat karena pada saat ini Bina Program tidak memiliki aktor dan role yang diusulkan oleh penulis sehingga yang memiliki kuasa untuk menunjuk siapakah yang dapat menjalankan skenario tersebut adalah kepala sub bagian bina program. Dalam uji coba ini, penulis akan secara langsung memantau penggunaan SOP. Dari situ penulis akan mencatat hasil uji coba penggunaan SOP dan melakukan survey kepada pihak Bina Program mengenai hasil dari uji coba penggunaan SOP pengelolaan insiden. Apabila masih saja terdapat kesalahan maka penulis akan melakukan perbaikan dan melakukan uji coba ulang hingga sesuai dengan kebutuhan Bina Program. Luaran dari aktivitas ini berupa dokumen SOP pengelolaan insiden.

\section{Hasil dan Pembahasan}

\subsection{Penggalian Data}

Dalam menyusun interview protocol, penulis menggunakan standar acuan kerangka kerja aktivitas dalam proses Incident Management menurut kerangka kerja ITIL V3. Beberapa poin penting yang akan diajukan kepada interviewee/narasumber adalah:

1) Seputar aktor dan role yang bertanggungjawab terhadap manajemen insiden GRMS

2) Insiden yang sering terjadi pada GRMS. Hal ini untuk memastikan apakah insiden tersebut lebih kepada software maintenance atau pemeliharaan data

3) Penyebab insiden layanan TI yang sering terjadi pada GRMS

4) Kondisi kekinian pengelolaan manajemen insiden GRMS, mulai dari mengidentifikasi insiden, pencatatan insiden, mengkategorisasikan insiden, prioritas insiden, diagnosis awal, eskalasi insiden, diagnosis dan investigasi, resolusi dan penutupan insiden. 
5) Kondisi ideal pengelolaan manajemen insiden GRMS, mulai dari mengidentifikasi insiden, pencatatan insiden, mengkategorisasikan insiden, prioritas insiden, diagnosis awal, eskalasi insiden, diagnosis dan investigasi, resolusi dan penutupan insiden.

Adapun berita acara wawancara kepada narasumber disampaikan sebagai berikut:

1) Wawancara dilakukan pada tanggal 13 April 2016 kepada admin dari aplikasi $e$-Controlling dan $e$ Project

2) Wawancara dilakukan pada tanggal 13 April 2016 kepada admin dari aplikasi e-Delivery

3) Wawancara dilakukan pada tanggal 14 April 2016 kepada admin dari aplikasi e-Budgeting

4) Wawancara dilakukan pada tanggal 18 April 2016 kepada admin dari aplikasi e-Performance

Hasil penggalian data diantaranya:

1) Masing-masing GRMS memiliki satu atau lebih penanggung jawab yang berperan sebagai admin serta helpdesk. Sebagai contoh pada aplikasi e-Controlling, e-Project dan e-Delivery. Untuk aplikasi $e$ Performance mereka memiliki 2 admin, yaitu super admin dan admin SKPD. Berdasarkan dari hasil wawancara pada poin pertanyaan 2 dan 3 mengenai aktivitas yang menjadi tanggung jawab dan pengelolaan insiden GRMS, maka dapat disimpulkan bahwa tugas dan fungsi setiap role/peran adalah sebagai berikut: a) Super Admin/Admin Bagian Bina Program; b) Admin SKPD; dan c) User.

2) Layanan TI pada GRMS pada dasarkan dikategorisasikan mejadi 2 kategori yaitu: a) Teknis: dukungan terhadap permasalahan terkait software, hardware maupun jaringan; dan b) Non teknis: dukungan terhadap permasalahan terkait dengan user dan alur proses bisnis.

\subsection{Analisis Kondisi Kekinian dengan Kondisi Ideal}

Pada bagian ini, peneliti melakukan analisis kondisi kekinian berdasarkan hasil penggalian data kemudian memetakan kondisi tersebut dengan kondisi ideal standar acuan. Dalam melakukan analisis, penulis mengacu pada 4 aspek penting dalam mendesain sebuah layanan TI berdasarkan tahapan service design ITIL V3, yaitu People, Processes, Product dan Partners [4]. Dalam penelitan, penulis menggunakan aspek people, processes dan product. Berikut adalah kondisi kekinian dan kondisi ideal berdasarkan aspek yang digunakan dan aktivitas pada incident management ITIL V3:

Tabel 1. Kondisi Kekinian GRMS dan Kondisi Ideal Pengelolaan insiden berdasarkan Kerangka Kerja ITIL V3

\begin{tabular}{|c|c|c|c|}
\hline Aspek & Aktivitas & Kondisi Kekinian & Kondisi Ideal \\
\hline \multirow{5}{*}{ Proses } & Incident Identification & $\begin{array}{l}\text { Admin sebagai orang pertama yang } \\
\text { berhubungan dengan user. Metode yang } \\
\text { digunakan adalah telepon, walk-in dan } \\
\text { chat. }\end{array}$ & $\begin{array}{l}\text { Pelaksana terbagi atas service desk, } \\
\text { manajemen aplikasi dan manajemen level } \\
\text { support }\end{array}$ \\
\hline & Incident Logging & $\begin{array}{l}\text { Admin GRMS berusaha mengerjakan } \\
\text { insiden langsung tanpa adanya } \\
\text { pencatatan }\end{array}$ & $\begin{array}{l}\text { Untuk mengelola insiden dengan benar } \\
\text { maka semua insiden harus sepenuhnya } \\
\text { tercatat }\end{array}$ \\
\hline & Incident Categorization & $\begin{array}{l}\text { Insiden dibagi menjadi dua yaitu teknis } \\
\text { dan non teknis. }\end{array}$ & $\begin{array}{l}\text { Secara umum dikategorisasikan jenis } \\
\text { layanan, komponen, hingga spesifik } \\
\text { incident-nya. }\end{array}$ \\
\hline & Prioritising Incident & $\begin{array}{l}\text { Prioritas tidak dilakukan dengan baik. } \\
\text { tidak ada standar prioritas yang jelas. }\end{array}$ & $\begin{array}{l}\text { Prioritas penanganan insiden dapat } \\
\text { ditentukan berdasarkan besarnya dampak } \\
\text { ataupun urgensitas }\end{array}$ \\
\hline & Initial Diagnosis & $\begin{array}{l}\text { Hampir semua admin GRMS } \\
\text { melakukan penanganan secara langsung } \\
\text { terhadap insiden yang masuk. }\end{array}$ & $\begin{array}{l}\text { Service desk akan berupaya menyelesaikan } \\
\text { insiden terlebih dahulu sebelum } \\
\text { meneruskan kepada manajemen aplikasi }\end{array}$ \\
\hline
\end{tabular}




\begin{tabular}{|c|c|c|c|}
\hline \multirow[t]{2}{*}{ Aspek } & Aktivitas & \multirow[t]{2}{*}{ Kondisi Kekinian } & \multirow{2}{*}{$\begin{array}{r}\text { Kondisi Ideal } \\
\text { atau manajemen level support }\end{array}$} \\
\hline & & & \\
\hline & Incident Escalation & $\begin{array}{l}\text { Insiden teknis maka diteruskan ke } \\
\text { developer. Insiden tersebut non teknis } \\
\text { maka diteruskan ke kepala Sub Bagian } \\
\text { Bina Program. }\end{array}$ & $\begin{array}{l}\text { Apabila service desk tidak dapat } \\
\text { menemukan solusi maka akan diteruskan } \\
\text { kepada tim lain atau ke level manajemen } \\
\text { yang lebih tinggi }\end{array}$ \\
\hline & $\begin{array}{l}\text { Investigation } \\
\text { Diagnosis }\end{array}$ & $\mathrm{n}$ & $\begin{array}{l}\text { Tindakan investigasi dilakukan untuk } \\
\text { menemukan sumber masalah dari insiden }\end{array}$ \\
\hline & Resolution and Recovery & resolusi sudah berjalan cukup baik. & $\begin{array}{l}\text { Merupakan tindakan yang diambil untuk } \\
\text { menyelesaikan suatu insiden }\end{array}$ \\
\hline & Incident Closure & $\begin{array}{l}\text { Penutupan dilakukan oleh admin } \\
\text { melalui telepon kepada user. }\end{array}$ & $\begin{array}{l}\text { Service desk menginformasikan kepada } \\
\text { pengguna bahwa insiden telah teratasi dan } \\
\text { setuju laporan insiden ditutup. }\end{array}$ \\
\hline Produk & $\begin{array}{l}\text { Pencatatan atau } \quad \log \\
\text { insiden }\end{array}$ & $\begin{array}{l}\text { Setiap aplikasi GRMS telah memiliki } \\
\text { aplikasi pencatatan insiden. Aplikasi } \\
\text { tersebut bernama } e \text {-trac. }\end{array}$ & $\begin{array}{l}\text { Adanya pencatatan insiden dan } \log \text { insiden } \\
\text { baik pendokumentasian manual maupun } \\
\text { elektronik }\end{array}$ \\
\hline
\end{tabular}

Dalam aspek people, yang menangani insiden adalah admin, developer dan kepala sub bagian bina program. Sehingga pada penelitian ini penulis mengusulkan adanya penambahan aktor dan role yaitu service desk sebagai single point of contact dengan pengguna yang akan dipaparkan lebih lanjut pada Subbagian Analisis Kesenjangan.

\subsection{Analisis Kesenjangan}

Pada bagian ini, penulis melakukan analisis kesenjangan untuk mengetahui kelemahan atau kekurangan dari kondisi kekinian terhadap kondisi ekspektasi maupun kondisi ideal berdasarkan standar acuan. Berikut adalah paparan mengenai analisis kesenjangan:

Tabel 2. Hasil Analisis Kesenjangan

\begin{tabular}{|c|c|c|c|}
\hline Aspek & Aktivitas & Kesenjangan Proses & Perubahan \\
\hline \multirow[t]{5}{*}{ Proses } & $\begin{array}{l}\text { Incident } \\
\text { Identification }\end{array}$ & $\begin{array}{l}\text { Diperlukan usulan penamabahan role dan } \\
\text { aktor baru beserta penjelasannya }\end{array}$ & $\begin{array}{l}\text { Terdapat penjelasan mengenai tugas } \\
\text { pokok dan fungsi aktor baru yaitu } \\
\text { penambahan aktor service desk operator } \\
\text { dan manajemen aplikasi }\end{array}$ \\
\hline & Incident Logging & $\begin{array}{l}\text { Diperlukan pencatatan terhadap log } \\
\text { histori insiden dan alur pencatatan insiden }\end{array}$ & $\begin{array}{l}\text { Terdapat kebutuhan dalam melakukan } \\
\text { dokumentasi pencatatan }\end{array}$ \\
\hline & $\begin{array}{l}\text { Incident } \\
\text { Categorization }\end{array}$ & $\begin{array}{l}\text { Diperlukan pendefinisian yang jelas } \\
\text { mengenai kategorisasi major dan minor } \\
\text { berdasarkan Incident Management ITIL } \\
\text { V3 dan penambahan prosedur untuk } \\
\text { menangani insiden dengan kategori major }\end{array}$ & $\begin{array}{l}\text { Terdapat penjelasan mengenai } \\
\text { kategorisasi yang jelas dan benar }\end{array}$ \\
\hline & $\begin{array}{l}\text { Prioritising } \\
\text { Incident }\end{array}$ & $\begin{array}{l}\text { Diperlukan pendefinisian yang jelas } \\
\text { mengenai prioritas insiden yang jelas } \\
\text { menurut Incident Management ITIL V3 } \\
\text { beserta matrixnya }\end{array}$ & $\begin{array}{l}\text { Terdapat penjelasan mengenai prioritas } \\
\text { insiden yang jelas dan benar }\end{array}$ \\
\hline & Initial Diagnosis & $\begin{array}{l}\text { Diperlukan alur yang jelas mengenai } \\
\text { penangan insiden menurut standar acuan } \\
\text { yaitu Incident Management ITIL V3. }\end{array}$ & $\begin{array}{l}\text { Terdapat kebutuhan } \\
\text { penanganan insiden beserta alur yang } \\
\text { jelas }\end{array}$ \\
\hline
\end{tabular}




\begin{tabular}{|c|c|c|c|}
\hline Aspek & Aktivitas & Kesenjangan Proses & Perubahan \\
\hline & Incident Escalation & $\begin{array}{l}\text { Diperlukan pemberian rincian alur } \\
\text { mengenai eskalasi insiden maupun alur } \\
\text { dari pengelolaan insiden itu sendiri dan } \\
\text { penjelasan mengenai pelevelan sesuai } \\
\text { dengan ITIL V3 }\end{array}$ & $\begin{array}{l}\text { Terdapat kebutuhan mengenai kebijakan } \\
\text { eskalasi beserta aktor dan role yang } \\
\text { melaksanakan dan ketentuan eskalasi. }\end{array}$ \\
\hline & $\begin{array}{l}\text { Investigation and } \\
\text { Diagnosis }\end{array}$ & $\begin{array}{l}\text { Diperlukan pemberian rincian alur } \\
\text { mengenai investigation and diagnosis; }\end{array}$ & $\begin{array}{l}\text { Terdapat kebutuhan dalam melakukan } \\
\text { penanganan insiden }\end{array}$ \\
\hline & $\begin{array}{l}\text { Resolution and } \\
\text { Recovery }\end{array}$ & resolution and recovery & \\
\hline \multirow[b]{2}{*}{ Produk } & Incident Closure & $\begin{array}{l}\text { Diperlukan alur yang jelas mengenai } \\
\text { penangan insiden menurut standar acuan } \\
\text { yaitu Incident Management ITIL V3. }\end{array}$ & $\begin{array}{l}\text { Terdapat kebutuhan dalam melakukan } \\
\text { penanganan insiden dan formulir } \\
\text { penutupan insiden }\end{array}$ \\
\hline & $\begin{array}{l}\text { Pencatatan atau } \log \\
\text { insiden }\end{array}$ & $\begin{array}{l}\text { Diperlukan pencatatan terhadap log } \\
\text { histori insiden. }\end{array}$ & $\begin{array}{l}\text { Terdapat kebutuhan dalam melakukan } \\
\text { dokumentasi pencatatan insiden dan alrur } \\
\text { yang jelas dalam penanganan insiden } \\
\text { baik dalam pencatatan manual maupun } \\
\text { elektronik }\end{array}$ \\
\hline
\end{tabular}

Dalam aspek People, penulis hanya memberikan usulan penambahan aktor beserta role-nya. Untuk kedepannya apakah usulan tersebut dipakai oleh Bina Program atau tidak itu semua tergantung kebijakan mereka. Usulan yang diberikan oleh penulis adalah penambahan service desk. Gambar 2 menjelaskan usulan tersebut.

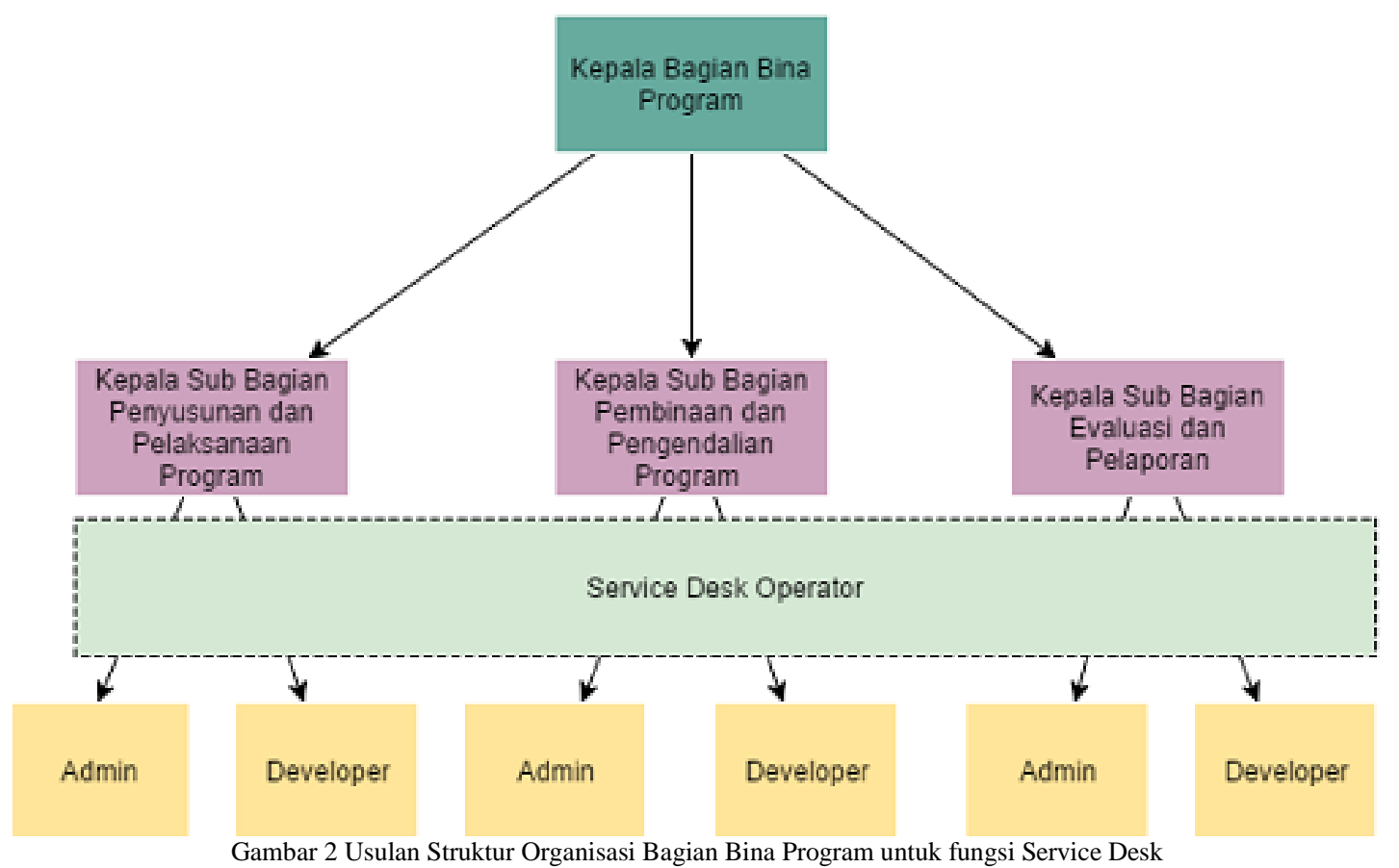

Selain analisis kesenjangan, akan diidentifikasi pula dampak dan perubahan dari adanya identifikasi perubahan pada analisis kesenjangan. Solusi tersebut dijadikan dasar dalam pembuatan aktivitas dalam 
Prosedur Operasional Standar (SOP). Berikut adalah identifikasi dampak dan solusi dari analisis kesenjangan.

Tabel 3. Hasil Dampak dan Solusi

\begin{tabular}{|c|c|c|c|}
\hline Aspek & Aktivitas & Dampak atas Proses & Solusi \\
\hline \multirow[t]{16}{*}{ Proses } & \multirow[t]{2}{*}{ Incident Identification } & $\begin{array}{l}\text { Penambahan aktor dan role baru } \\
\text { terhadap SDM }\end{array}$ & $\begin{array}{l}\text { Pembuatan usulan tambahan } \\
\text { tupoksi baru yaitu service desk } \\
\text { operator }\end{array}$ \\
\hline & & $\begin{array}{l}\text { Adanya aktivitas untuk mencatat } \\
\text { pelaporan insiden dalam formulir } \\
\text { pelaporan insiden }\end{array}$ & $\begin{array}{l}\text { Pembuatan formulir pelaporan } \\
\text { insiden }\end{array}$ \\
\hline & \multirow[t]{5}{*}{ Incident Logging } & $\begin{array}{l}\text { Adanya dokumen baru yang berisi } \\
\text { bukti laporan insiden }\end{array}$ & $\begin{array}{l}\text { 1) Pembuatan dokumen yang } \\
\text { berisi laporan insiden }\end{array}$ \\
\hline & & & $\begin{array}{l}\text { 2) Penyediaan teknologi terkait } \\
\text { untuk melakukan pencatatan } \\
\text { insiden }\end{array}$ \\
\hline & & $\begin{array}{l}\text { Adanya penjabaran mengenai } \\
\text { penambahan peran masing-masing } \\
\text { SDM }\end{array}$ & $\begin{array}{l}\text { Pembuatan usulan tambahan } \\
\text { tupoksi baru yaitu service desk } \\
\text { operator }\end{array}$ \\
\hline & & $\begin{array}{l}\text { Adanya aktivitas dalam melakukan } \\
\text { pencatatan dan penanganannya dalam } \\
\text { formulir } l o g \text { insiden }\end{array}$ & Pembuatan formulir $\log$ insiden \\
\hline & & $\begin{array}{l}\text { Adanya alur penulisan kategorisasi } \\
\text { insiden }\end{array}$ & $\begin{array}{l}\text { Pembuatan alur kategorisasi } \\
\text { insiden }\end{array}$ \\
\hline & \multirow{2}{*}{ Incident Categorization } & $\begin{array}{l}\text { Adanya penjabaran mengenai } \\
\text { kategorisasi insiden }\end{array}$ & $\begin{array}{l}\text { Pembuatan penjelasan kategorisasi } \\
\text { insiden }\end{array}$ \\
\hline & & $\begin{array}{l}\text { Adanya alur penulisan prioritas } \\
\text { insiden }\end{array}$ & Pembuatan alur prioritas insiden \\
\hline & \multirow{2}{*}{ Prioritising Incident } & $\begin{array}{l}\text { Adanya penjabaran mengenai } \\
\text { prioritas insiden }\end{array}$ & $\begin{array}{l}\text { Pembuatan penjelasan prioritas } \\
\text { insiden }\end{array}$ \\
\hline & & $\begin{array}{l}\text { Adanya penjabaran mengenai } \\
\text { penangan insiden dengan kategori } \\
\text { major }\end{array}$ & $\begin{array}{l}\text { Pembuatan prosedur penanganan } \\
\text { insiden yang harus dilakukan setiap } \\
\text { saat ada insiden yang masuk }\end{array}$ \\
\hline & \multirow[t]{2}{*}{ Initial Diagnosis } & $\begin{array}{l}\text { Adanya penjabaran mengenai } \\
\text { penambahan peran masing-masing } \\
\text { SDM dalam melakukan penanganan } \\
\text { insiden }\end{array}$ & $\begin{array}{l}\text { Pembuatan usulan tambahan } \\
\text { tupoksi baru bagi SDM dalam } \\
\text { melakukan penanganan insiden }\end{array}$ \\
\hline & & $\begin{array}{l}\text { Adanya penjabaran mengenai } \\
\text { eskalasi insiden }\end{array}$ & $\begin{array}{l}\text { Pembuatan penjelasan dan } \\
\text { prosedur eskalasi }\end{array}$ \\
\hline & Incident Escalation & $\begin{array}{l}\text { Adanya penjelasan aktor dan role } \\
\text { baru terhadap SDM untuk eskalasi } \\
\text { insiden }\end{array}$ & $\begin{array}{l}\text { Pembuatan usulan tambahan } \\
\text { pelevelan eskalasi insiden baru }\end{array}$ \\
\hline & $\begin{array}{l}\text { Investigation } \quad \text { and } \\
\text { Diagnosis; Resolution and } \\
\text { Recovery }\end{array}$ & $\begin{array}{l}\text { Adanya aktivitas dalam melakukan } \\
\text { insiasi solusi dan menyelesaikan } \\
\text { insiden dengan solusi yang telah } \\
\text { ditemukan }\end{array}$ & $\begin{array}{l}\text { Pembuatan alur aktivitas dalam } \\
\text { melakukan pencarian solusi, } \\
\text { menginisiasi solusi r dan } \\
\text { menyelesaikan insiden terhadap } \\
\text { solusi yang telah ditemukan }\end{array}$ \\
\hline & Incident Closure & $\begin{array}{l}\text { Adanya aktivitas dalam melakukan } \\
\text { penutupan insiden dan mengisikan } \\
\text { formulir penutupan insiden }\end{array}$ & $\begin{array}{l}\text { Pembuatan formulir penutupan } \\
\text { insiden }\end{array}$ \\
\hline
\end{tabular}




\subsection{Pembuatan Dokumen SOP}

Pembuatan Prosedur Operasional Standar (SOP) disusun berdasarkan hasil analisis kesenjangan yang telah dilakukan. Pembuatan SOP mengacu kepada aktivitas incident management berdasarkan kerangka kerja ITIL V3 sementara format SOP berdasarkan Peraturan Menteri Pendayagunaan Aparatur Negara dan Reformasi Birokrasi Republik Indonesia Nomor 35 Tahun 2012 Tentang Pedoman Penyusunan Standar Operasional Prosedur Administrasi Pemerintahan dan Peraturan Walikota Surabaya Nomor 73 tahun 2012.

Gambar 3 dan 4 menjelaskan aktivitas dalam Prosedur Operasional Standar (SOP) yang disusun berdasarkan aktivitas pada incident management berdasarkan kerangka kerja ITIL V3.

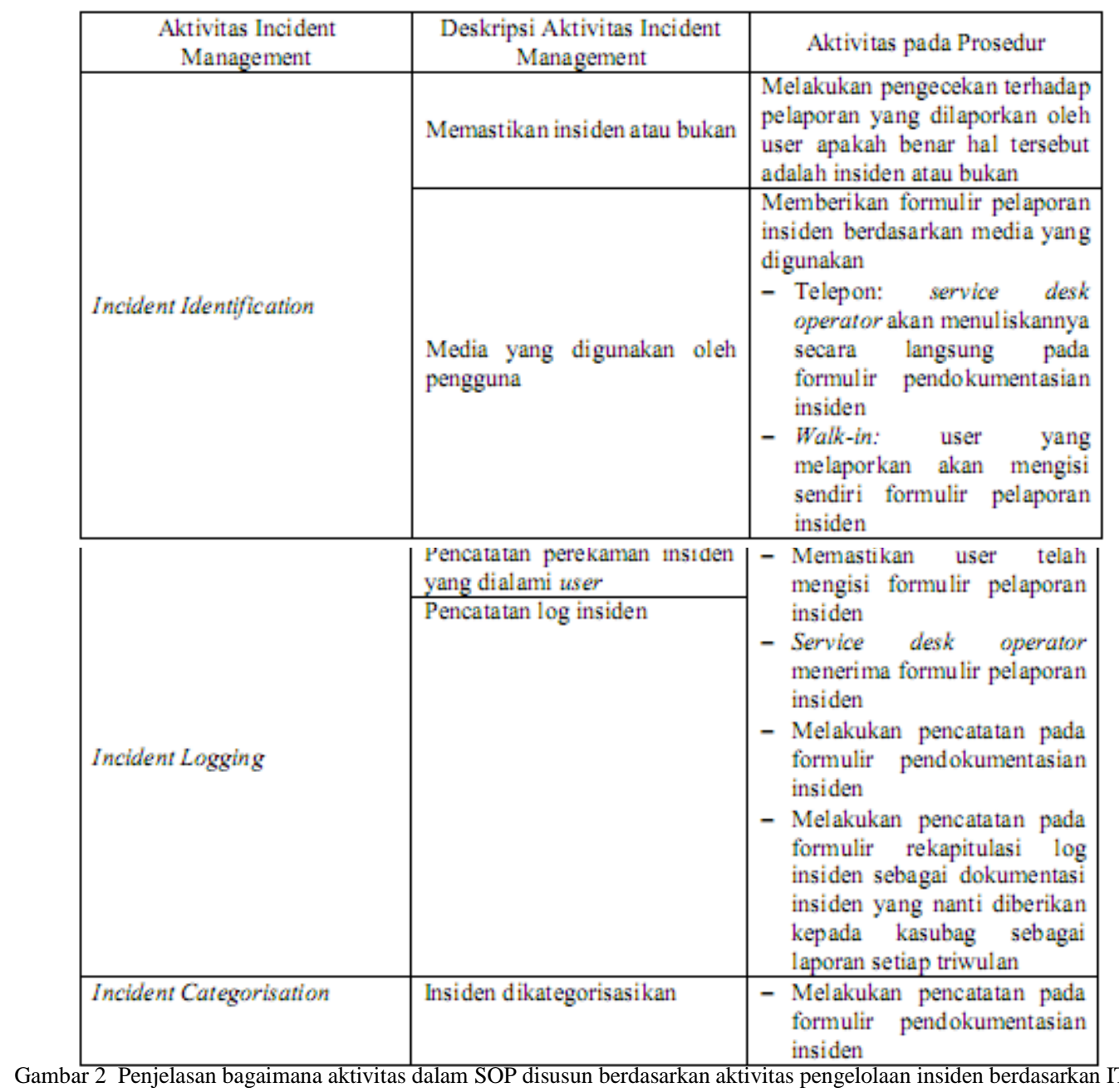

Aktivitas yang telah diidentifikasi tersebut dikembangkan dalam dokumen SOP dengan mengacu format Peraturan Menteri Pendayagunaan Aparatur Negara dan Reformasi Birokrasi Republik Indonesia Nomor 35 Tahun 2012 Tentang Pedoman Penyusunan Standar Operasional Prosedur Administrasi Pemerintahan dan Peraturan Walikota Surabaya Nomor 73 tahun 2012. Tabel 4 adalah rincian SOP yang dibuat. 


\begin{tabular}{|c|c|c|}
\hline $\begin{array}{l}\text { Aktivitas Incident } \\
\text { Management }\end{array}$ & $\begin{array}{c}\text { Deskripsi Aktivitas Incident } \\
\text { Management }\end{array}$ & Aktivitas pada Prosedur \\
\hline & & $\begin{array}{l}\text { - Melakukan kategorisasi } \\
\text { insiden sesuai dengan } \\
\text { kategori yang disediakan }\end{array}$ \\
\hline \multirow[b]{2}{*}{ Prioritising Incident } & $\begin{array}{l}\text { Memastikan kategorisasi } \\
\text { insiden dilakukan }\end{array}$ & \multirow{2}{*}{$\begin{array}{l}\text { - Melakukan pencatatan pada } \\
\text { formulir pendokumentasian } \\
\text { insiden } \\
\text { - Melakukan prioritas insiden } \\
\text { sesuai dengan prioritas yang } \\
\text { telah disediakan }\end{array}$} \\
\hline & Memberi prioritas insiden & \\
\hline Initial Diagnosis & $\begin{array}{lll}\text { Melakukan } & \text { diagnosis } & \text { awal } \\
\text { terhadap } & \text { insiden } & \text { yang } \\
\text { dilaporkan } & & \end{array}$ & $\begin{array}{l}\text { - Mencari diagnosis awal dan } \\
\text { solusi sementara terhadap } \\
\text { insiden yang telah dilaporkan } \\
\text { - Melakukan analisis insiden } \\
\text { dan mencatatnya pada } \\
\text { formulir pendokumentasian } \\
\text { insiden pada kolom yang } \\
\text { telah disediakan } \\
\text { - Apabila service deskoperator } \\
\text { dapat menangani insiden } \\
\text { tersebut sendiri maka tidak } \\
\text { perlu melakukan kebijakan } \\
\text { eskalasi }\end{array}$ \\
\hline \multirow[b]{2}{*}{ Incident Escalation } & $\begin{array}{l}\text { Melakukan } \\
\text { escalation }\end{array}$ & \multirow{2}{*}{ 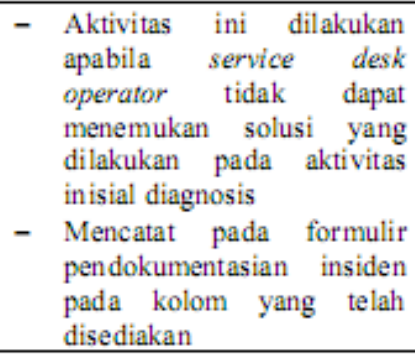 } \\
\hline & $\begin{array}{l}\text { Melakukan } \quad \text { hierarchical } \\
\text { escalation }\end{array}$ & \\
\hline \multirow[t]{2}{*}{$\begin{array}{l}\text { Investigation and Diagnosis, } \\
\text { Resolution dan Recovery }\end{array}$} & \multirow[t]{2}{*}{$\begin{array}{l}\text { Melakukan inisiasi dari solusi } \\
\text { sementara dan menyelesaikan } \\
\text { insiden dari solusi yang telah } \\
\text { ditetapkan }\end{array}$} & $\begin{array}{l}\text { - Melakukan inisiasi solusi } \\
\text { sementara untuk insiden }\end{array}$ \\
\hline & & 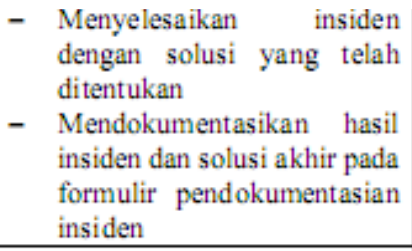 \\
\hline \multirow{2}{*}{ Incident Closure } & $\begin{array}{l}\text { Memberikan laporan status } \\
\text { selesainya insiden }\end{array}$ & \multirow{2}{*}{ 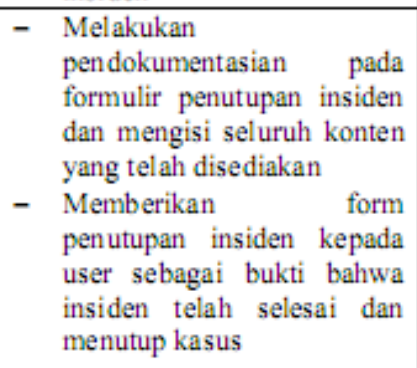 } \\
\hline & $\begin{array}{l}\text { Memastikan pengguna puas } \\
\text { dengan penanganan insiden } \\
\text { dan mensetujui adanya } \\
\text { penutupan insiden }\end{array}$ & \\
\hline
\end{tabular}

Gambar 4 Penjelasan bagaimana aktivitas dalam SOP disusun berdasarkan aktivitas pengelolaan insiden berdasarkan ITIL V3 (lanjutan) 
Tabel 4. Hasil SOP Pengelolaan insiden

\begin{tabular}{|c|c|c|c|c|c|}
\hline Nomor SOP & \multicolumn{3}{|c|}{ Nama SOP } & Nomor Formulir & Nama Formulir \\
\hline $\begin{array}{l}\text { SOP-Insiden- } \\
001\end{array}$ & \multicolumn{3}{|c|}{ SOP Penanganan Insiden } & $\begin{array}{l}\text { 1) FRM-Insiden-001 } \\
\text { 2) FRM-Insiden-002 }\end{array}$ & $\begin{array}{l}\text { 1) Formulir Pelaporan Insiden } \\
\text { 2) Formulir Pendokumentasian Insiden }\end{array}$ \\
\hline $\begin{array}{l}\text { SOP-Insiden- } \\
002\end{array}$ & $\begin{array}{l}\text { SOP I } \\
\text { Incident }\end{array}$ & $\begin{array}{l}\text { Penanganan } \\
t\end{array}$ & Major & 3) FRM-Insiden-003 & 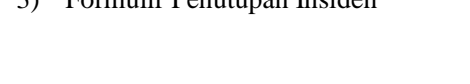 \\
\hline $\begin{array}{l}\text { SOP-Insiden- } \\
003\end{array}$ & $\begin{array}{l}\text { SOP } \\
\text { Insiden }\end{array}$ & Rekapitulasi & $\log$ & FRM-Insiden-004 & Formulir Rekapitulasi Log Insiden \\
\hline
\end{tabular}

SOP yang disusun dideskripsikan secara singkat sebagai berikut:

1) SOP Penanganan Insiden: merupakan SOP yang berisi aktivitas pengelolaan dan penyelesaian insiden.

2) SOP Penanganan Major Incident: merupakan SOP yang berisi aktivitas penanganan insiden yang terkhususkan untuk insiden dengan kategorisasi major

3) SOP Rekapitulasi Log Insiden: merupakan SOP yang berisi aktivitas pencatatan rekapitulasi seluruh insiden yang telah masuk

\subsection{Verifikasi dan Validasi}

Kegiatan verifikasi SOP dilakukan untuk mengetahui ketepatan dan kesesuaian aktivitas maupun struktur dan konten formulir yang ada di dalam dokumen SOP. Penulis melakukan verifikasi SOP dengan melakukan wawancara kepada Admin/Super Admin Bina Program dan Kepala Sub Bagian Pembinaan dan Pengendalian Bagian Bina Program. Berdasarkan hasil verifikasi SOP yang telah dilakukan, terdapat beberapa perbaikan dalam dokumen SOP. Perbaikan tersebut adalah:

1) Perubahan Peran dan Tanggung Jawab Level Jabatan

Berdasarkan hasil verifikasi SOP yang telah dilakukan, perlu dilakukan perubahan peran dan tanggung jawab level jabatan Kepala Sub Bagian Penyusunan Pelaksanaan Program, Kepala Sub Bagian Pembinaan dan Pengendalian, dan Kepala Sub Bagian Evaluasi dan Pelaporan.

2) Perubahan Pada Penjelasan Prioritas Insiden

Berdasarkan hasil verifikasi SOP yang telah dilakukan, perlu dilakukan perbaikan pada prioritas insiden. Karena menurut admin GRMS dan Kepala Sub Bagian Bina Program prioritas yang dibuat kurang jelas dan kurang spesifik sehingga membingungkan dan tidak mudah dimengerti.

Kegiatan validasi SOP dilaukan untuk mengetahui apakah SOP yang dihasilkan penulis dapat digunakan secara langsung dalam aktivitas manajemen insiden GRMS. Selain itu dengan adanya validasi SOP, dapat diketahuo kekurangan dan feedback dari pelaksana SOP terkait SOP yang telah dihasilkan. Dalam melakukan validasi SOP, penulis menggunakan simulasi sebagai metode validasi dan disertai keikutsertaan pelaksana SOP dalam simulasi. Dalam simulasi ini yang menunjuk sebagai pelaksana simulasi adalah Kepala Sub Bagian Pembinaan dan Pengendalian Bagian Bina Program dikarena pelaksana yang diusulkan oleh penulis memang belum tersedia pada Bina Program. Tidak semua skenario yang dibuat oleh penulis dilakukan oleh validator. Karena saat pada saat itu, validator melakukan validasi pada real case yang terjadi saat itu dan case tersebut bukan merupakan insiden major. Berdasarkan hasil validasi SOP yang telah dilakukan, terdapat beberapa perbaikan yang perlu dilakukan. Adapun perbaikan yang dilakukan adalah: Penambahan kolom No. Telepon pada Formulir Pelaporan Insiden, Formulir Pendokumentasian Insiden, Formulir Rekapitulasi Log Insiden dan Formulir Penutupan Insiden. Gambar 5 menunjukkan hasil validasi yang dilakukan pada Admin E-Delivery Bagian Bina Program. 


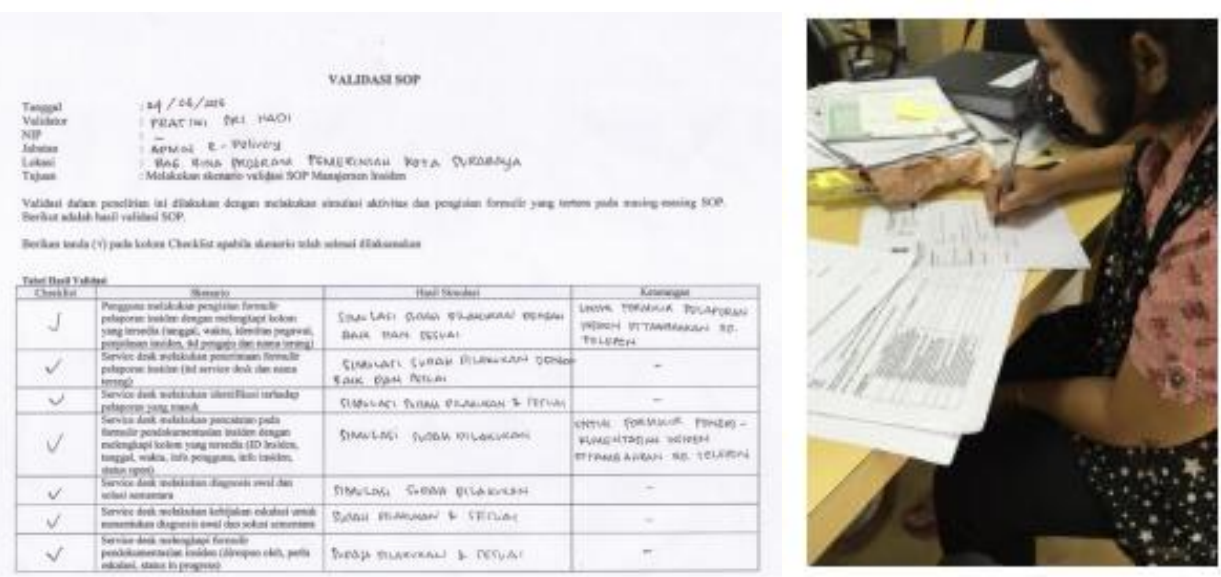

Gambar 5 Dokumentasi validasi SOP di Bagian Bina Program

\section{Kesimpulan}

1) Untuk kondisi saat ini yang menangani pengelolaan insiden GRMS adalah admin, developer dan kasubag. Saat ini pencatatan insiden yang dilakukan tidak tercatat dengan baik dan admin GRMS lebih menyukai untuk menyegerakan pengerjaan insiden. Prioritas insiden di Bina Program sudah dilakukan, hanya saja prioritas tersebut kurang jelas dan tidak standar. Untuk eskalasi insiden sudah dilakukan, hanya saja saat ini belum ada standar khusus dan kebijakannya.

2) Adanya usulan penambahan aktor dan role yaitu service desk sebagai single point of contact dengan pengguna, bertanggung jawab terhadap insiden yang terjadi, melakukan diagnosis awal dan solusi sementara terhadap insiden. Adanya penambahan penjelasan matrix prioritas, penambahan aktivitas untuk menangani insiden major dan adanya penambahan aktivitas rekapitulasi log insiden yang harus dilakukan setiap tiga bulan sekali. Selain itu juga terdapat usulan kebijakan eskalasi dengan memberikan pelevelan yang sesuai dengan standar acuan dengan menambahkan usulan aktor manajemen aplikasi sebagai $2^{\text {nd }}$ level support, vendor sebagai $3^{\text {rd }}$ level support dan kasubag sebagai manajemen level support.

3) Berdasarkan analisis kesenjangan, dibuatlah sebanyak 3 (tiga) usulan SOP dibuat berdasarkan standar acuan ITIL V3 - Incident Management yang dilengkapi dengan formulir pendukung. SOP dasar dalam pengelolaan insiden adalan SOP Penanganan Insiden sementara SOP Penanganan Major Incident diperlukan untuk kondisi khusus yang berkaitan dengan service desk operator dan manajemen aplikasi. SOP yang rutin dilakukan sebagai bentuk pelaporan adalah SOP Rekapitulasi $\log$ Insiden.

4) Hasil verifikasi dan validasi yang dilakukan dihasilkan bahwa SOP yang dibuat dapat diimplementasikan kedepannya oleh Bina Program, hanya saja untuk saat ini SOP tersebut masih belum secara langsung diimplementasikan karena terkait aktor yang tidak dimiliki oleh Bina Program.

\section{Daftar Rujukan}

[1] B. P. K. Surabaya, Dokumen Profil Bagian Bina Program Kota Surabaya, Surabaya: Bina Program Kota Surabaya, 2015.

[2] A. Holil and S. Paradongan, "Sistem Manajemen Insiden pada Program Manajemen Insiden dan Dukungan TI Berdasarkan Framework ITIL V3 (Studi Kasus pada Biro Teknologi Informasi BPK-RI)," pp. 1-10, 2010.

[3] B. T. Kota, "Standard Operating Procedure (SOP)," Peraturan Menteri, vol. I, no. 44, pp. 7-12, 2008.

[4] R. W. Griffin, Manajemen, Jakarta: Erlangga, 2004.

[5] W. R. Wicaksana, A. Herdiyanti, T.D. Susanto, “ Pembuatan Standar Operasional Prosedur (SOP) Manajemen Akses Untuk Aplikasi E-Performance Bina Program Kota Surabaya Berdasarkan Kerangka Kerja ITIL V3 Dan ISO 27002”, Jurnal SISFO, Vol. 06, No.01, pp. $105-120,2016$.

[6] B. K. D. K. Semarang, Pedoman Penyusunan Administrasi Pemerintah, BKD Kota Semarang, 2012.

[7] UCISA, ITIL - Introducing Service Operation, University of Oxford, 2002. 
[8] B. Orand, Foundation of IT Service Management with ITIL 2011, USA: ITILYaBrady, 2011.

[9] B. Hermana, "Teknik Analisis Masalah: GAP Analysis dan SWOT Analysis," gunadarma, 10 Januari 2015. [Online]. Available: http://pena.gunadarma.ac.id/teknik-analisis-masalah-gap-analysis-dan-swot-analysis/. [Accessed 26 Januari 2016]. 
Ammyra Fatma Rizky et al. / Jurnal Sisfo Vol.06 No.02 (2017) 199-214

Halaman ini sengaja dikosongkan 